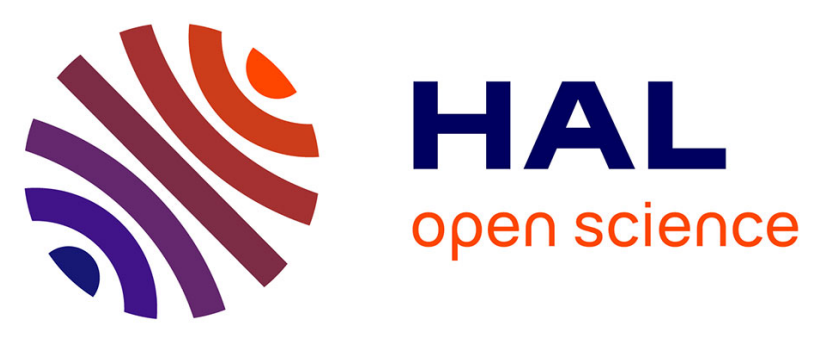

\title{
Flow cytometry immunophenotyping of fine-needle aspiration specimens: utility in the diagnosis and classification of non Hodgkin lymphomas.
}

Susana Barrena, Julia Almedia, Maria-Carmen Garcia-Macias, Antonio Lopez, Ana Rasillo, Jose-María Sayagues, Rosa-Ana Rivas, Maria-Laura Gutiérrez, Juana Ciudad, Teresa Flores, et al.

\section{To cite this version:}

Susana Barrena, Julia Almedia, Maria-Carmen Garcia-Macias, Antonio Lopez, Ana Rasillo, et al.. Flow cytometry immunophenotyping of fine-needle aspiration specimens: utility in the diagnosis and classification of non Hodgkin lymphomas.. Histopathology, 2011, 58 (6), pp.906. 10.1111/j.13652559.2011.03804.x . hal-00626294

\section{HAL Id: hal-00626294 https://hal.science/hal-00626294}

Submitted on 25 Sep 2011

HAL is a multi-disciplinary open access archive for the deposit and dissemination of scientific research documents, whether they are published or not. The documents may come from teaching and research institutions in France or abroad, or from public or private research centers.
L'archive ouverte pluridisciplinaire HAL, est destinée au dépôt et à la diffusion de documents scientifiques de niveau recherche, publiés ou non, émanant des établissements d'enseignement et de recherche français ou étrangers, des laboratoires publics ou privés. 


\section{Histopathology}

\section{Flow cytometry immunophenotyping of fine-needle aspiration specimens: utility in the diagnosis and classification of non Hodgkin lymphomas.}

\begin{tabular}{|c|c|}
\hline Journal: & Histopathology \\
\hline Manuscript ID: & HISTOP-04-10-0239.R1 \\
\hline Wiley - Manuscript type: & Original Article \\
\hline $\begin{array}{r}\text { Date Submitted by the } \\
\text { Author: }\end{array}$ & 26-Jul-2010 \\
\hline Complete List of Authors: & $\begin{array}{l}\text { BARRENA, SUSANA; Servicio General de Citometría, Departamento } \\
\text { de Medicina and Centro de Investigación del Cáncer (IBMCC- } \\
\text { CSIC/USAL) } \\
\text { ALMEDIA, JULIA; Servicio General de Citometría, Departamento de } \\
\text { Medicina and Centro de Investigación del Cáncer (IBMCC- } \\
\text { CSIC/USAL) } \\
\text { GARCIA-MACIAS, MARIA-CARMEN; Hospital Universitario de } \\
\text { Salamanca, Departamento de Anatomía Patológica } \\
\text { LOPEZ, ANTONIO; Servicio General de Citometría, Departamento } \\
\text { de Medicina and Centro de Investigación del Cáncer (IBMCC- } \\
\text { CSIC/USAL) } \\
\text { RASILLO, ANA; Servicio General de Citometría, Departamento de } \\
\text { Medicina and Centro de Investigación del Cáncer (IBMCC- } \\
\text { CSIC/USAL) } \\
\text { SAYAGUES, JOSE-MARÍA; Servicio General de Citometría, } \\
\text { Departamento de Medicina and Centro de Investigación del Cáncer } \\
\text { (IBMCC-CSIC/USAL) } \\
\text { RIVAS, ROSA-ANA; Servicio General de Citometría, Departamento } \\
\text { de Medicina and Centro de Investigación del Cáncer (IBMCC- } \\
\text { CSIC/USAL) } \\
\text { GUTIÉRREZ, MARIA-LAURA; Servicio General de Citometría, } \\
\text { Departamento de Medicina and Centro de Investigación del Cáncer } \\
\text { (IBMCC-CSIC/USAL) } \\
\text { CIUDAD, JUANA; Servicio General de Citometría, Departamento de } \\
\text { Medicina and Centro de Investigación del Cáncer (IBMCC- } \\
\text { CSIC/USAL) } \\
\text { FLORES, TERESA; Hospital Universitario de Salamanca, } \\
\text { Departamento de Anatomía Patológica } \\
\text { BALANZATEGUI, ANA; Hospital Universitario de Salamanca, Unidad } \\
\text { de Biología Molecular. Servicio de hematología } \\
\text { Caballero, María-Dolores; Hospital Universitario de Salamanca, } \\
\text { Servicio de Citometria } \\
\text { ORFAO, ALBERTO; FUNDACIÓN CENTRo DE INVESTIGACIÓN DEL } \\
\text { CÁNCER, OF MEDICINE }\end{array}$ \\
\hline
\end{tabular}


Keywords: fine-needle aspiration , flow cytometry, cytology / histology, B cell non-Hodgkin lymphoma, WHO classification

\section{SCHOLARONE \\ Manuscripts}




\section{HISTOPATHOLOGY}

July $26^{\text {th }}, 2010$

Ref.: Manuscript HISTOP-04-10-0239-Revised version 1 (R1)

Dear Dra. MacDonald,

Please find attached a revised version (R1) of the manuscript ID HISTOP-04-10-0239 entitled "Flow cytometry immunophenotyping of fine-needle aspiration specimens: utility in the diagnosis and classification of non Hodgkin lymphomas" by Barrena et al, which has been modified following the suggestions and comments of the reviewers.

Attached you will also find a point-by-point list of the changes that have been introduced which are related to the comments of the two reviewers.

We hope, in its present format, the manuscript is now acceptable for publication in your prestigious journal.

Looking forward to hearing from you at your earliest convenience.

Yours sincerely,

Prof. Alberto Orfao MD PhD

Centro de Investigación del Cáncer

Avenida de la Universidad de Coimbra $s / n$

37007-Salamanca. Spain

Telephone number: +34923294811

Fax number: +34 923294795

E-mail: orfao@usal.es 


\section{ANSWER TO THE COMMENTS OF THE REVIEWERS:}

\section{REVIEWER \#1:}

Comment 1.- Abstract; page 2, "antibody combination used did not allow the diagnosis of Hodgkin lymphoma" - how was HL reported by FCM ie equivocal result, reactive, nonclassifiable?

Answer to comment 1.- New sentences have been added in the results and discussion sections of the new revised version of the manuscript in which it is clearly stated that flow cytometry immunophenotyping could not distinguish $\mathrm{HL}$ infiltration from reactive lymph nodes and thus they were classified together by flow cytometry (pages 11 and 15). The sentence from the abstract has also been modified, following the comment of the reviewer.

Comment 2.- Introduction; page 4, use of FCM alone would presuppose that if adopted cytology, being according to the results inferior than FCM, would not be of help, in which case why would it be inspected. The authors fall short of suggesting this as a possible outcome to the work. Furthermore, as cytology alone is known to be inferior to histological analysis and if it is accepted that superior FCM analysis would obviate need for cytology should the key comparison not be between FCM and histology which, whilst made, is in much for the results rather hidden amongst the other data relating to cytology?

Answer to comment 2.- As stated above in the answer to comment 1, cytological analysis of FNA was superior to flow cytometry immunophenotyping in distinguishing between $\mathrm{HL}$ and reactive lymph node tissues at a screening phase done in FNA samples. The complementary nature of cytology and flow cytometry analysis in the screening of FNA samples is now more clearly explained in a new sentence added in the discussion section of the manuscript (page 15). 
Comment 3.- Methods: page 6, the antibody panel used for histological IHC is much smaller than for FCM which may have a bearing on diagnostic accuracy. This is key as histological subtype is presently taken as "gold standard". Furthermore details of diagnostic review of histological diagnosis, if any, are not included. These points should be addressed as correct histological diagnosis is critical for interpretation of the results.

Answer to comment 3.- A new sentence in which information about the review process of histological diagnose has been added in the material and methods section of the new version of the manuscript, following the indication of the reviewer. In addition, a sentence in which the potential impact of limited IHC antibody panels vs usage of a higher number of immunophenotypic markers by flow cytometry on the diagnostic classification of malignancy is discussed, has also been added in the discussion section of the revised manuscript (pages 7 and 17).

Comment 4.- Results: page 8, in "concordant diagnosis between conventional cytology and FCM immunophenotyping was obtained in 372/399 FNA samples (93\%); in 140 of these samples, diagnosis was further confirmed by histological studies" does this infer that of the 161 samples for which histology was available concordance with FCM was present for 140 ie $87 \%$ ? If so then this should be stated more expliciity as this is a key finding.

Answer to comment 4.- Following the suggestion of the reviewer, the sentence in which the concordance results between cytology, flow cytometry and histology are described has been modified to clarify the percentage of concordance between flow cytometry and histopathological diagnosis (page 9).

Comment 5.- Results: page 9, "7/11 cases diagnosed with B-NHL", it is not clear to what 11 cases this refers, especially following closely on the 140 concordant cases noted above. This, and other instances of the same make interpretation of the detail of the results difficult to follow and rather confusing, though the authors do provide summary of the data which is helpful in this regard. 
Answer to comment 5.- The sentences presenting results in page 9 have been modified in order to more clearly describe the discrepancies observed (page 9).

\section{REVIEWER \#2:}

Comment 1.- The FCM approach appears to have a very high specificity and sensitivity for $T$ NHL but there are no additional markers listed for classifying T-NHL other than the basic $C D 3 / 4 / 8 / 56$ markers from the screening tube. Were these markers sufficient for identifying $T$ NHL or were additional markers used, that are not included in the supplementary data?

Answer to comment 1.- Information about the specific markers used for classification of T-cell neoplasias, in addition to those included in the screening flow cytometry combination of monoclonal antibodies, is now provided in the Material and Methods section of the new revised version of the manuscript, as supplementary data (Supplementary Table1a).

Comment 2.- There needs to be a clear description of how the FCM diagnosis was made, for example what markers were used to classify $T$-NHL, to distinguish BL from DLBCL etc. Whilst the full antibody list should remain as a supplementary table, this information needs to be in the main document.

Answer to comment 2.- Following the indication of the reviewer, a more clear description of the immunophenotypic criteria used to define distinct $\mathrm{T}$ - and B-cell entities is now provided in the Material and Methods section of the revised version of the manuscript (bottom of page 6 and first part of page 7)

Comment 3.- The higher specificity of FCM in classifying FL, DLBCL, and BL appears to relate to a few cases where the histopathological diagnosis was DLBCL whilst FCM more accurately predicted FL/BL. It may be helpful to explain in more detail why the cases with morphology (and presumably Ki67) that was consistent with DLBL ended with a final diagnosis of FL. Is the FCM diagnosis made independently of iFISH data and if so would the authors suggest that FCM could also replace the need for iFISH? I think the data would need to be much stronger before 
the claim that FCM is more sensitive/specific than excision biopsy IHC for any disease category could be widely accepted.

Answer to comment 3.- A new sentence has been added in both the results and discussion sections of the new revised version of the manuscript, in which the discrepancies observed among cases with histological diagnosis of DLBCL are described and discussed in more detail. Also, it is now clearly stated in the discussion section that FCM diagnosis was made independently of iFISH data, but we do not recommend at all at this point replacement of iFISH by the immunophenotypic study (pages 12, 16, 17top and 17bottom).

Comment 4.- This group recently reported a very high rate of detection of monoclonal B-cells in the peripheral blood of healthy individuals and such a finding appears to have very little clinical significance. There are apparently no false positive cases reported in this series, yet in the discrepant cases there are several where FCM detects B-NHL/clonal B-cells and the cytology and histology indicate a reactive process or are not informative. In these cases the final diagnosis is considered to fit with the FCM but is it not possible that these are incidental findings unrelated to the cause of the lymphadenopathy?

Answer to comment 4.- A new sentence has been added in the results section of the revised version of the manuscript in which it is clearly stated that in none of the FNA samples analysed by flow cytometry, small populations that could reflect "false positive" results by immunophenotyping (similar to e.g. MBL in peripheral blood samples), were detected (page 10).

Comment 5.- A number of markers used in FCM appear to be intended for investigating HL. Can the authors inform why FCM was uninformative for this condition?

Answer to comment 5.- Following the reviewer's comment, a new sentence has been added in the discussion section of the revised version of the manuscript in which the limited utility of the $\mathrm{HL}$-associated markers used in the present study is discussed (page 15) 
Comment 6.- The Ki67 reagent used for immunohistochemistry is not reported.

Answer to comment 6.- Information about the specific Ki67 reagent used has been added in Supplementary Table $1 \mathrm{~b}$ of the revised version of the manuscript, following the indication of the reviewer.

\section{ASSOCIATE EDITOR:}

There were no comments to the authors by the Associate Editor 
Title: Flow cytometry immunophenotyping of fine-needle aspiration specimens: utility in the diagnosis and classification of non Hodgkin lymphomas.

Authors: Susana BARRENA ${ }^{1}$, Julia ALMEIDA ${ }^{1}$, María del Carmen GARCÍAMACIAS $^{2}$, Antonio LÓPEZ ${ }^{1}$, Ana RASILLO ${ }^{1}$, Jose María SAYAGUÉS ${ }^{1}$, Rosa Ana RIVAS $^{1}$, María Laura GUTIÉRREZ ${ }^{1}$, Juana CIUDAD ${ }^{1}$, Teresa FLORES ${ }^{2}$, Ana BALANZATEGUI $^{3}$, María Dolores CABALLERO ${ }^{4}$ and Alberto ORFAO ${ }^{1}$

\section{Institutions:}

${ }^{1}$ Servicio General de Citometría, Departamento de Medicina and Centro de Investigación del Cáncer (IBMCC-CSIC/USAL), Universidad de Salamanca, Salamanca, Spain.

${ }^{2}$ Departamento de Anatomía Patológica, Hospital Universitario de Salamanca, Salamanca, Spain.

${ }^{3}$ Unidad de Biología Molecular. Servicio de Hematología, Hospital Universitario de Salamanca, Salamanca, Spain.

${ }^{4}$ Servicio de Hematología, Hospital Universitario de Salamanca, Salamanca, Spain

Running head: Utility of FCM analysis on FNA specimens.

Grants and sources of support: This work has been partially supported by the RTICC RD06/0020/0035-FEDER, and FIS 08/90881 grants, from the Fondo de Investigación Sanitaria, Instituto de Salud Carlos III, Ministerio de Ciencia e Innovación, Madrid, Spain. JM Sayagués is supported by CP05/00321 grant, from the Instituto de Salud Carlos III, Ministerio de Ciencia e Innovación, Madrid, Spain.

Key Words: fine-needle aspiration, flow cytometry, cytology, histology, B cell nonHodgkin lymphoma, WHO classification.

\section{Corresponding author:}

Prof. Alberto Orfao, MD, PhD

Centro de Investigación del Cancer

Paseo de la Universidad de Coimbra S/N

37007 Salamanca, Spain

Tel: +34-923 294811 Fax: +34-923294795

E-mail: orfao@usal.es 


\begin{abstract}
AIM: To establish the utility of flow cytometry (FCM) for screening and diagnosis of B-cell non Hodgkin lymphoma (B-NHL) from lymphoid tissue samples obtained by fine-needle aspiration (FNA).

METHODS/RESULTS: we prospectively compared FCM vs cytology/histology analysis of FNA samples for the diagnostic screening and further WHO subclassification of B-NHL. FCM and cytology showed a high degree of agreement (93\%); however, diagnosis of reactive processes (RP), B-NHL and T-NHL by FMC showed higher sensitivity than cytology (92\%-100\% vs 64-94\%, respectively), without false positive NHL cases; the antibody combination used did not allow positive diagnosis of Hodgkin lymphoma as distinct from RP. A high concordance rate was found between FCM and histopathology (74\%) in subtyping B-NHL. In this regard, mantle-cell lymphoma and chronic lymphocytic leukemia showed the highest degree of agreement (100\% concordant rates). In turn, FCM showed higher sensitivity/specificity in classifying follicular lymphoma (FL) and large B-cell lymphomas, while the opposite occurred for marginal-zone and lymphoplasmacytic lymphomas.

CONCLUSIONS: FCM enhances the diagnostic ability of FNA cytology, playing a crucial role in a rapid and accurate differential diagnosis between RP, B-NHL, and T-NHL. In addition, immunophenotyping of FNA samples contributes to a more precise subclassification of B-NHL when combined with histopathology and genetic/molecular data.
\end{abstract}




\section{INTRODUCTION}

Diagnosis and classification of malignant lymphoma into WHO categories are essential steps in the clinical management of chronic B-cell leukemias and lymphomas ${ }^{1}$. For decades now, fine-needle aspiration (FNA) cytology has been proposed as a useful tool for the diagnostic screening of patients with easily accessible enlarged lymph nodes for early, cost-effective distinction between benign/reactive and malignant disease conditions ${ }^{2-15}$. More recently, combined usage of cytology and flow cytometry (FCM) immunophenotyping analysis of FNA samples has been found to contribute to an improved classification of B-cell non-Hodgkin lymphomas (B-NHL) into WHO categories, specially for low grade B-cell lymphomas ${ }^{11-13,16-20}$. In contrast, the accuracy of FNA alone vs excisional biopsy for both primary diagnosis and classification of malignant lymphoma remains controversial ${ }^{21-24}$. Although many studies have reported concordance rates between FNA-studies and histology of $>80 \%$ (range: $76 \%$ to $97 \%$ ) ${ }^{6}$ $10,12-13,16,18-19,25-31$, it is recommended that analysis of FNA samples should not replace tissue biopsy studies, because of the existence of false negative cases in all reported series. In turn, very heterogeneous results have been reported regarding the contribution of FNA studies vs lymph node histology for the diagnostic subclassification of B-NHL with concordance rates of between $<50 \%$ to $87 \%$, depending on the type of lymphoma 12-13, 16-20, 28; in this regard FNA-based studies are frequently considered to be of limited utility for the classification of lymphoma, because they do not provide information on the histology of the tumor ${ }^{24,32-34}$. Thus, at present no consensus agreement exits about the precise utility of FNA evaluation for the diagnosis and subclassification of malignant lymphoma; although it is clear that in many instances it may obviate the need for tissue biopsy, these situations have not been precisely established, with a few exceptions (i.e. for documenting disease recurrence, assessment of transformation into a 
higher tumor grade and when open biopsy is impractical) $2,5,7,30,35$. In addition, the information about the independent value of FMC immunophenotyping versus conventional cytological analyses of FNA samples on the diagnostic screening of lymphoma is limited $13,20,25,36-37$, as most reports have focused on the utility of FNA cytology combined with FCM vs histopathology.

In this study we prospectively evaluated the potential contribution of FCM immunophenotyping ( $v s$ conventional cytological and histological studies) in the diagnostic screening of FNA samples, and, in further subclassification of B-NHL into specific WHO categories.

\section{MATERIAL AND METHODS}

Patients and samples. A total of 448 consecutive fine-needle aspiration (FNA) samples from 400 patients -213 males (53\%) and 187 (47\%) females- were prospectively studied in parallel at both the Cytometry and Pathology Services of the University Hospital of Salamanca (Salamanca, Spain), between February 2002 and October 2007. Mean age of patients at the moment of entering the study was of $53 \pm 22$ years (range: 3 to 96 years); 321 cases were analyzed at diagnosis, and 79 (all corresponding to patients previously diagnosed with NHL) were studied at relapse $(n=77)$ or at disease progression $(n=2)$. In most patients $(n=374)$ only one sample was studied, while two, three and four samples were analyzed in 18, 6 and 2 cases, respectively. According to final diagnosis, samples were distributed as follows: reactive process (RP), 155; Hodgkin`s lymphoma (HL), 29; B-NHL, 132; T-NHL, 12; solid tumor (ST), 49; plasma cell malignancy (PCM), 14; acute myeloblastic leukemia (AML), 2; T-cell acute lymphoblastic leukemia (T-ALL), 5; and blastic plasmacytoid 
dendritic cell neoplasm (pDCN), 1. The remaining 49 samples were not evaluable by flow cytometry $(n=14)$ and/or conventional cytology $(n=46)$.

Most specimens $(\mathrm{n}=370)$ corresponded to lymph node FNA, while the remaining 78 specimens corresponded to subcutaneous $(n=38)$, breast $(n=8)$ and thyroid nodules $(n=5)$, to mediastinal $(n=5)$, abdominal $(n=3)$, renal $(n=2)$, palate $(n=2)$, pulmonary, retroperitoneal, parotid, ocular orbit, scapular, inguinal, thigh and infratemporalesphenoidal masses $(n=1$, each), to an hepatic nodule and to suprahyoid, urinary tract, testis, transbronchial, gum and sternum lesions $(\mathrm{n}=1$, each). Each sample was collected after informed consent was given by each subject and the study was approved by the Ethics Committee of the University Hospital of Salamanca.

Cytomorphologic and immunocytochemical analyses. FNA specimens were collected by an experienced cytopathologist, using $20-\mathrm{mL}$ syringes equipped with a syringed holder and a 23 gauge-needle $(0.6 \times 25 \mathrm{~mm})$, as described elsewhere ${ }^{16,38-40}$. Either 2 or 3 air-dried, ethanol-fixed smears were stained from each FNA sample using Papanicolaou and/or haematoxylin-eosin (H\&E) ${ }^{41-44}$, for conventional cytological analyses. Whenever indicated, immunocytochemistry was performed for disease classification after smears had been fixed with methanol and stained, with appropriate monoclonal antibodies (MAb) as previously described ${ }^{45}$ (supplementary Table 1b). All slides were assessed by an experienced cytopathologist.

Immunophenotypic studies. Half of each FNA specimen was placed in $1 \mathrm{ml}$ of a sterile saline solution, and immediately processed for further FCM immunophenotyping. Briefly, samples $(100 \mu \mathrm{L})$ were stained using a direct immunofluorescence stain-and-then-lyse technique, previously described in detail ${ }^{46}$, with the following four or five-color combination of seven (or eight) fluorochromeconjugated MAb -fluorescein isothiocyanate (FITC)/ phycoerytrhin (PE)/ peridin 
chlorophyll protein (PerCP)/ allophycocyanin (APC) (and allophycocyanin-cyanin7

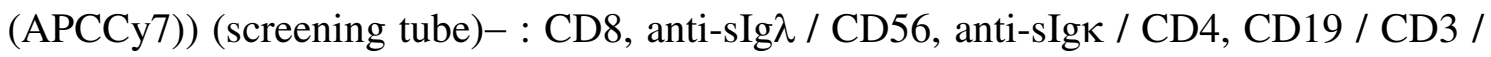
(CD45) (supplementary Table 1a). In addition to the MAb reagents, $100 \mu \mathrm{L}$ of premixed Perfect Count ${ }^{\mathrm{TM}}$ beads (Cytognos SL, Salamanca, Spain) were added to each stained specimen immediately prior to its FCM measurement, to calculate absolute cell counts 47-48. After staining, samples were run at low speed on either a FACSCalibur or a FACSCantoII flow cytometer- Becton/Dickinson Biosciences, San José, CA, USA(BDB), and information stored about all events corresponding to nucleated cells present in the sample. For data analysis, the INFINICYT ${ }^{\mathrm{TM}}$ software program (Cytognos SL) was used.

Antigen expression was used to identify the different types of cells present in the sample and they were classified as negative (-), dimly positive $(+d)$, positive $(+)$ and strong positive $(++)$ using arbitrary relative linear mean fluorescence intensity (MFI) cut-off values of $1-5,5-10^{1}, 10^{1}-10^{2}$ and $>10^{2}$ (data obtained with the FACSCalibur analogical flow cytometer; scale range: $10^{0}$ to $10^{4}$ ) and of $0-10^{2}, 10^{2}-10^{3}, 10^{3}-10^{4}$ and $>10^{4}$ (data obtained with the FACSCantoII digital flow cytometer; scale range: 0 to 264,144). FCM B-cell (mono)clonality was defined by a surface immunoglobulin (sIg) kappa/sIg lambda ratio of either $>3$ or $<0.5^{17,31}$. T-cell (mono)clonality was suspected by $\mathrm{FCM}$ whenever a $\mathrm{CD} 4 / \mathrm{CD} 8$ ratio $>4$ or $<0.7$ was found, a major $\mathrm{CD} 4+/ \mathrm{CD} 8+$ or CD4-/CD8- T-cell population was detected, and/or an otherwise aberrant T-cell population was identified (e.g. under-expression of CD3 or CD4). For those samples where presence of an aberrant/clonal cell population was suspected, the study was extended, with additional disease-oriented panels of reagents (Supplementary Table 1a), to confirm the immunophenotypic diagnosis. To classify B-NHL into specific disease categories according to the immunophenotypic pattern of clonal B-cells, recommended 
criteria according to the $\mathrm{WHO}$ classification ${ }^{1}$ were followed, together with previous data reported by our group ${ }^{46,49}$-e.g. the differential phenotypic profile for CD10, cytbcl2 and $\mathrm{CD} 38$ is useful to distinguish $\mathrm{BL}\left(\mathrm{CD} 10^{+/++} / \mathrm{cytbcl}^{-/+\mathrm{d}} / \mathrm{CD} 38^{++}\right)$, FL $\left(\mathrm{CD} 10^{+/++} / \mathrm{cytbcl}^{++} / \mathrm{CD} 38^{+\mathrm{d}}\right)$ and DLBCL $\left(\mathrm{CD} 10^{-/+} / \mathrm{cytbc12}^{-/+\mathrm{d}} / \mathrm{CD} 38^{+\mathrm{d}}\right)-$.

Histological and immunohistochemical analyses. Lymph node excision or biopsies from extranodal tissues were performed in 161 samples from 148 patients. Briefly, tissue specimens were fixed in $10 \%$ formaldehyde, embedded in paraffin and sliced into $3 \mu \mathrm{m}$-sections. Afterward, specimens were stained with H\&E and evaluated with an optical microscope (Nikon Y-THM, Tokio, Japan) using conventional approaches. Whenever appropriate, tissue sections were also stained by conventional immunohistochemistry (immunoperoxidase technique) ${ }^{50}$ using an immunostainer (Vision Biosystem, Newcastle, UK), with the MAb listed in the immunohistochemistry section of Supplementary Table 1b. Appropriate positive and negative controls were used in parallel. Two experienced pathologists routinely evaluated the slides; in addition, in case of any discrepancy (between histology, FCM and/or cytology), specimens were further reviewed a third time-and whenever required, frozen tissue sections re-stained-, to confirm the histological diagnosis.

Analysis of TCR and IGH gene rearrangements. In those samples in which discrepant diagnostic findings were obtained between FCM, cytology and/or histology, and either B- or T-cell clonality was suspected by one or more methods, TCRG and IGH gene rearrangements were assessed by well-established polymerase chain reaction (PCR) techniques ${ }^{51}$, using the BIOMED-2 TCRG $^{52}$ and combined IGH and IGK genebased probes and protocols, respectively ${ }^{53}$.

Interphase fluorescence in situ hybridization (iFISH) studies. Analysis of the genetic abnormalities associated with B-NHL or other B-cell chronic 
lymphoproliferative disorders (B-CLPD) was performed using multicolor iFISH techniques which have been previously described in detail ${ }^{54-55}$. The specific probes used for the detection of trisomy 12, del(11q22.3), del(11q23), del(17p13.1), del(6q21), $\operatorname{del}(7 q)$ and $\operatorname{del}(13 q 14.3)$, as well as $14 q 32$ gene rearrangement, $t(11 ; 18)(q 21 ; q 21)$, $\mathrm{t}(14 ; 18)(\mathrm{q} 32 ; \mathrm{q} 21), \quad \mathrm{t}(11 ; 14)(\mathrm{q} 13 ; \mathrm{q} 32), \mathrm{t}(8 ; 14)(\mathrm{q} 24 ; \mathrm{q} 32), \quad \mathrm{c}-\mathrm{MYC}$ and BCL6 gene rearrangements, are shown in supplementary Table $1 \mathrm{~b}$.

Statistical methods. Relative frequencies and median, mean, standard deviation (SD), range and the $25^{\text {th }}$ and $75^{\text {th }}$ percentiles were calculated using the SPSS software program (SPSS 15.0 Inc. Chicago, IL, USA) for categorical and continuous variables, respectively. Either the Mann-Whitney U or the Kruskal-Wallis tests were used to determine the statistical significance of the differences observed between two or more groups for non-paired continuous variables. P-values $\leq 0.05$ were considered to be associated with statistical significance.

The sensitivity, specificity, positive predictive value (PPV) and negative predictive value (NPV) were calculated using a subset of 167 cases which were analyzed in parallel by cytology, flow cytometry, and histopathology and, whenever required for the classification of the disease, also by cytogenetics/molecular techniques and clinical follow-up $(\mathrm{n}=48)$. Among other cases, this series included 82 patients with CLPD in which additional clinical/follow-up information was available for subclassification into specific WHO categories. Sensitivity was calculated as TP/TP+FN (TP: true positive cases; FN: false negative cases), specificity as TN/TN+FP (TN: true negative cases; FP: false positive cases), $\mathrm{PPV}$ as $\mathrm{TP} / \mathrm{TP}+\mathrm{FP}$ and NPV as $\mathrm{TN} / \mathrm{TN}+\mathrm{FN}$. 


\section{RESULTS}

The vast majority (89\%) of all 448 FNA samples investigated (n=399 samples from 364 patients) were considered to be informative by both cytology and FCM immunophenotyping (mean number of cells analyzed by FCM: $2.2 \times 10^{6} \pm 3.5 \times 10^{6}$; range: $4.2 \times 10^{2}$ to $\left.32 \times 10^{6}\right)$. The other $49(11 \%)$ samples corresponding to 36 patients, could not be evaluated due to insufficient material or peripheral blood (PB) contamination; from them, 3 samples were not evaluable by FCM, 35 were not adequate for cytological analyses, and 11 samples could not be analyzed by both techniques.

Diagnostic screening of FNA: Flow cytometry (FCM) immunophenotyping vs conventional cytology. A concordant diagnosis between conventional cytology and FCM immunophenotyping was obtained in 372/399 FNA samples (93\%); in 161 out of the total 399 samples, diagnosis was further confirmed by histological studies, among them, full concordance between cytology, histology and FCM was found in 140 (87\% of all specimens analyzed with histology) (Table 1).

Detailed description of the distribution of lymphocyte subsets in lymph node FNA samples with concordant diagnosis $(n=323)$ is shown in supplementary figure 1 , for the different diagnostic categories.

In the remaining 27 FNA samples (7\%) corresponding to 22 patients, discordant results were reported by FCM vs cytology and/or histology (Table 2). Overall, 15/22 discordant cases $(68 \%)$ were initially properly-classified by FCM, while in the remaining 7 cases, final diagnosis was concordant with that of either cytology and/or histology; most discordant cases $(n=20)$ had a final diagnosis of NHL (11 B-NHL and 4 T-NHL) or other hematological malignancies $(n=5)$; the remaining two cases corresponded to a final diagnosis of HL (Table 2). Among those 27 discordant samples, in 7/11 cases diagnosed with B-NHL (62\%; cases \#6 to \#12 in Table 2), final diagnosis 
of B-NHL was confirmed, as correctly suspected by FCM, but not by cytology. In the other 4/11 discordant B-NHL cases, FCM results were consistent with a RP (cases \#2, \#3, \#4 in Table 3) or RP vs ST (case \#5 in Table 3) but compatible with B-NHL by cytological and histological studies; unfortunately in these four later cases clonality could not be confirmed by PCR/FISH analyses. In turn, most discordant T-NHL cases (5/6) were correctly classified by FCM, with a negative cytology (Table 2). Thus, it should be emphasized that all cases initially classified by FCM as B-NHL and T-NHL were finally considered to have B- and T-NHL, respectively. The only exception was case\#11, in which coexistence of B- and T-NHL was detected by cytology/histology and confirmed by molecular techniques, while only the B-cell clone could be detected by FCM (Table 2). Similarly, the initial diagnosis made by FCM was confirmed in all other cases with a hematological malignancy other than NHL (i.e. AML, PCM and pDCN) (case \#17), the correct diagnosis was not suspected by FCM (diagnosis of ST was established while a RP was suspected by FCM). Noteworthy, in none of the FNA samples, small populations of B-NHL/clonal B-cells that could reflect "false positive" results by immunophenotyping (similar to e.g. monoclonal B-cell lymphocytosis in PB samples $)^{56}$, were detected.

In order to more precisely evaluate the utility of FCM vs conventional cytology for the diagnostic screening of FNA samples, we compared the sensitivity and specificity (and their corresponding predictive values) of both approaches in a subset of 167 samples (including 82 B-NHL/B-CLPD) in which complete histological, molecular/genetic, clinical and/or outcome data was available (Table 3). Overall, the sensitivity of FCM for the diagnosis of RP was higher than that of conventional cytology (100\% vs 94\%, respectively), with a similar specificity (96\% vs 94\%, respectively; Table 4). However, it should be noted that the FCM screening multicolor 
combination of MAb tested was not useful for the specific diagnosis of HL; consequently, FCM immunophenotyping could not distinguish HL infiltration from reactive lymph nodes and the former cases were thus classified together with RP by FCM. In addition, FCM was clearly more sensitive than conventional cytology for the diagnostic screening of CLPD (sensitivity of $96 \%$ vs $94 \%$ for B-NHL and of $92 \%$ s $64 \%$ for T-NHL, respectively), while both approaches showed a similar specificity (Table 3). Similarly, the specificity of FCM for the diagnosis of ST was 100\%, although its sensitivity decreased to $95 \%$ vs $100 \%$ by conventional cytology (Table 3, upper panel).

Role of FCM immunophenotyping of FNA samples vs histopathology in the sub-classification of B-NHL into WHO categories. A total of 82 FNA samples from 71 patients with an established diagnosis of B-CLPD who had complete clinico-biological, haematological, histopathological, immunophenotypic and molecular/genetic data at diagnosis, were included in this part of the study. For these cases the overall concordance rate between FCM and conventional histology was of 74\% (61/82) with the following distribution according to specific WHO categories: follicular lymphoma (FL), 25/31 (81\%) cases; diffuse large B-cell lymphoma (DLBCL), 15/19 (79\%); mantle cell lymphoma (MCL), 9/9 (100\%); B-cell chronic lymphocytic leukemia (CLL), 4/4; Burkitt lymphoma (BL), 3/4; lymphoplasmacytoid lymphoma (LPL), 3/5; MALT (mucosa-associated lymphoid tissue)-lymphoma, 1/3; prolymphocytic leukemia (PLL), 1/1 splenic marginal zone lymphoma (sMZL), 1/1 (case), and; nodal marginal zone lymphoma (nMZL) 0/3. The remaining two samples corresponded to the CLL-like clone from case \#8 (see Table 2) and to the BL-like clone from case \#6 (see Table 2); both B-cell populations were detected by FCM but not by histology. 
Discrepant results were observed between FCM and histopathology in 21 FNA samples (26\%), corresponding to 18 patients (Table 4). Discordant diagnoses corresponded to FL (n=6/31, 19\%), BL (n=1/4), nMZL (n=3/3), MALT lymphoma $(n=2 / 5), \operatorname{sMZL}(n=1 / 1)$, DLBCL $(n=4 / 19,21 \%)$ and LPL $(n=2 / 5$ cases $)$. Three of 6 discrepant FL cases (cases\#3, \#4, and \#5) were correctly classified by FCM, while diagnosed as DLBCL by histology; despite these three cases showed a diffuse growth pattern and relatively a high Ki67 expression, in addition to the presence of a typical phenotypic pattern of FL $\left(\mathrm{CD} 10^{+/++} / \mathrm{cytbcl} 2^{++} / \mathrm{CD} 38^{+\mathrm{d}}\right)$ in the samples analyzed, by both histology and FCM in parallel, histological diagnosis of FL made in other enlarged lymph nodes together with the patient behavior during follow-up were definitive to classify case \#3 as FL, while the presence of $\mathrm{t}(14 ; 18)+$ (in the absence of BCL6 gene rearrangements) in all tumor cells supported the diagnosis of FL in cases \#4 and \#5. In another two discrepant FL cases (cases\#1 and \#2), the opposite happened. However, it should be noted that these later two cases (cases\#1 and \#2, in Table 4) displayed an atypical FL phenotype (e.g. presence of CD10 without over-expression of cytBcl2 in case \#2), and genetic features -absence of $t(14 ; 18)$-. The other case (case \#6) was a relapsed FL with $\mathrm{t}(14 ; 18)$ in the absence of c-MYC gene rearragements, which was diagnosed as compatible with BL by both histology and FCM. One BL case with cMYC gene rearrangements was correctly suspected by FCM but not by histology (case\#7, in Table 4). Similarly, all discrepant sMZL (case \#13, in Table 4), LPL (cases \#17 and \#18, in Table 4) and DLBCL cases (cases \#14 and \#15, in Table 4) were correctly suspected by FCM. Conversely, with the extended B-cell characterization panel of MAb used, FCM could not specifically assign 3/3 nMZL (cases \#8 to \#10, in Table 4) and 2/3 MALT lymphomas (cases \#11 and \#12, in Table 4) into specific small 
cell WHO diagnostic categories and it could just exclude diagnosis of other WHO BNHL subtypes (Table 4).

Overall, the assignment of B-NHL to specific WHO diagnostic categories provided by FCM (vs histopathology) was confirmed in 10/18 discrepant cases (56\% vs 38\%), corresponding to $12 / 21$ samples (57\% vs 33\%). Accordingly, FCM showed a greater sensitivity (91\%; range: $94 \%$ to $100 \%$ ) than histopathology ( $84 \%$; range: $75 \%$ to $100 \%)$ for the majority of B-NHL subgroups (Table 3) including FL (94\% vs 87\%), DLBCL (100\% vs 79\%), and BL (100\% vs 75\%). In contrast, the sensitivity of histopathology was higher than that of FCM (67\% vs 33\%) for MALT and marginal zone lymphomas. In turn, the specificity of FCM was similar to that of histopathology (range: $98 \%-100 \%$ vs 92\%-100\%, respectively) for all WHO groups of B-NHL (Table 3). Diagnosis of MCL and CLL was correctly suspected by both FCM and histology in all cases.

\section{DISCUSSION}

At present, the contribution of FNA studies to the diagnosis of lymphoproliferative disorders is well-established 6, 8, 20, 27, mainly when FCM is combined with cytology $8,12,18,27-28,37,57-58$. However, most studies aiming at the assessment of the utility of FNA on primary diagnosis of tissue samples have compared the utility of combining FCM and cytology vs cytology alone ${ }^{11-12}$, while very few reports have focused on the comparison between FCM alone $v s$ cytology ${ }^{20,36,59}$. In turn, the efficiency of FNA analyses in the diagnosis and classification of lymphoma without examination of tissue sections remains controversial ${ }^{6,8,14,16,22,26,31,60-61}$. In the present study we attempted to determine the precise contribution of FCM immunophenotyping applied to the study of FNA samples for both primary diagnosis of 
enlarged lymphoid and other tissues and further subclassification of B-NHL into specific WHO disease entities.

In a first step we compared FCM vs cytology FNA analysis. In this regard, it should be noted that both techniques could be applied to most samples. However, similarly to what has been described for other samples with low/limited cellularity (e.g. CSF) ${ }^{48}$ FCM was applicable to a higher percentage of cases than cytology, because of limited numbers of cells for microscopical analyses (data not shown). Among those samples in which the cells present in FNA samples could be evaluated by both techniques, our results showed a high degree of agreement between FCM -after applying the single-screening multicolor tube here described- and FNA cytology (plus histology, whenever available) with $<10 \%$ discrepant cases. Noteworthy, diagnosis of most discrepant cases was initially properly-oriented by FCM, while misclassified by cytology and/or histology, these including two thirds of discrepant B-NHL cases, all discrepant T-NHL and most discrepant hematological malignancies other than NHL. Overall, these results confirm and extend on previous observations about the utility of FCM analysis of FNA samples, performed in parallel to conventional cytological and histopathological studies 20, 31, 36, 59. Accordingly, even if used alone, FCM immunophenotyping showed a higher efficiency than conventional cytology, because of a greater sensitivity in the classification of RP, B-NHL and T-NHL, in the absence of false positive NHL cases. If we take into account that i) an approach used as a screening diagnostic tool would ideally have a high sensitivity (to identify all positive cases), ii) RP and NHL represent the vast majority of cases in whom FNA analysis of enlarged lymph nodes is indicated and, iii) no false positive T-NHL cases were detected by FCM, it could be concluded that FCM should be systematically performed on FNA samples for diagnostic screening purposes. In addition, to our knowledge, this is the first study 
that shows a higher efficiency of FCM vs conventional cytology/histology in the diagnosis of T-NHL. In fact, with few exceptions ${ }^{62}$ previous reports have indicated that immunophenotyping is not an adequate approach to diagnose T-NHL and that histopathology should be considered as the gold standard in this regard 6, 17-18, 20, 24, 27-28, 63-64. Conversely, cytological analysis of FNA was superior to FCM in distinguishing HL from reactive lymph nodes at this screening step, since the single multicolor tube used for immunophenotyping of FNA specimens did not allow discrimination between HL infiltration and RP. Based on this data, together with the above referred findings, it could be concluded -as also recommended by others ${ }^{6,14,27-28,37,57,65}$ - that combined usage of FCM immunophenotyping and conventional cytology would be mandatory for the diagnostic screening of FNA samples, since information provided by the two approaches is complementary, and not redundant.

In turn, alternative antibody panels ${ }^{66}$ should be also evaluated to investigate the utility of FCM in distinguishing RP vs HL in FNA samples. Then, the question remains about when to proceed to perform an excisional biopsy after diagnostic screening by FCM and conventional cytology had been done, on a FNA specimen. In this regard, it should be noted that although combined FCM and cytological analysis of FNA samples proved to be able to reliably distinguish between reactive and neoplastic conditions, 3/154 cases diagnosed as having a RP by both FCM and cytology (after excluding HL), developed a NHL (two B-cell and one T-cell NHL) after a median follow-up of 5 years (data not shown). Interestingly, histological analyses performed initially in all three cases were also consistent with a RP. In turn, two cases (\#4 and \#5 in Table 2) evaluated as RP by both FCM and conventional cytology were finally diagnosed with B-NHL (DLBCL) on histopathological grounds, because of a diffuse pattern of tissue infiltration by $\mathrm{CD} 20^{+} / \mathrm{Ki} 67^{+++}$large cells; although clinical follow-up showed a 
behavior consistent with NHL, neither B-cell clonality at the molecular level nor genetic abnormalities associated to large B-cell lymphoma could be demonstrated in both cases (data not shown). These results are in line with previous findings which indicate that the most common scenario for a false-negative FCM result occurs in large B-cell lymphomas, as viability of large neoplastic cells may rapidly drop during processing of

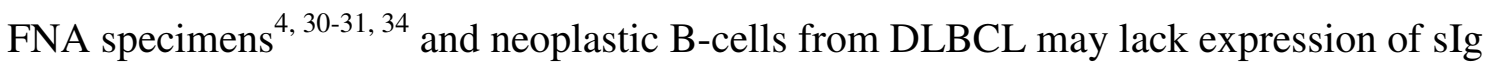
light chains $27,30,67$. Therefore, in case of high suspicion of NHL (particularly of aggressive B-cell NHL), biopsy of lymphoid tissue may be recommended after FNA analysis, even if FCM and conventional cytology are concordant with a diagnosis of RP.

At present, subclassification of B-NHL by FCM immunophenotyping of FNA alone is highly controversial $5,7-8,12-13,16,26-27,31,58,65,68$; when compared to histopathology analysis (considered as the gold-standard) the sensitivity and specificity of immunophenotyping of FNA specimens in subtyping B-NHL into specific WHO disease entities range between $63 \%-94 \%$ and $88 \%-100 \%$, respectively $12,13,31,37,58$ mostly depending on the type of lymphoma. In this regard, the specific B-NHL subtypes usually accounting for a higher rate of discrepant case include DLBCL, transformed FL and other aggressive lymphomas, including $\mathrm{BL}^{58,37,13}$, which it is not surprising, since it has been reported that morphology, immunophenotype and even genetics may overlap between DLBCL, BL and $\mathrm{FL}^{69}$, suggesting the existence of a clinicopathologic spectrum of some aggressive B-cell NHL, which is still not completely understood.

In contrast to most papers published in the literature, here we used the final WHO diagnosis (including histopathology, molecular/genetic data and clinical followup), instead of the histological diagnosis per se as the reference diagnosis to which FCM and cytological/histopathological findings were compared. Despite this, it should be emphasized that FCM diagnosis here presented were made independently of the 
genetic information provided by iFISH and any other molecular or clinical data. Overall, our results show a relatively high concordance rate between histopathology and FCM, with around one fourth of cases showing discrepant results. As it could be expected, those disease entities where immunophenotyping plays a greater role in their diagnosis (e.g. MCL and CLL) showed the highest concordance rate; this is probably related to the usage of a higher number of immunophenotypic markers by FCM which are of utility in such categories $v s$ the relatively limited IHC antibody panels. In turn, discrepant cases mostly comprised FL, DLBCL and BL (in line with previous studies ${ }^{13}$, 37, 58), in addition to marginal-zone and LPL lymphomas. Interestingly, the accuracy of FCM (in terms of both sensitivity and specificity) in classifying FL, DLBCL and BL was higher than that of cytology/histopathology, whereas the latter was more sensitive in the diagnosis of marginal-zone derived NHL. Altogether, these results suggest that both FCM and histology provide complementary information and that only in cases of MCL and CLL, the need for tissue biopsy could be omitted.

In summary, our results show that multiparameter FCM immunophenotyping significantly enhances the diagnostic ability of conventional cytological analysis of FNA, playing a crucial role in a rapid and accurate differential diagnosis between RP, B-NHL, T-NHL and other hematological malignancies. In addition, further more detailed FCM immunophenotype characterization of FNA samples also contributes to a more precise diagnostic subclassification of B-NHL into WHO-disease entities, when combined with histopathology and genetic/molecular data.

Author contribution: SB performed research, analyzed data and wrote the paper; JA designed research, analyzed data and wrote the paper; MCGM selected the cohort of individuals and analyzed data; AL and JC analyzed data; AR, JMS, RA, MLG, TF and 
$\mathrm{AB}$ contributed to perform the techniques, and $\mathrm{AO}$ designed research, analyzed data and wrote the paper. 


\section{REFERENCES}

1. Swerdlow SH, Campo E, Harris NL, Jaffe ES, Pileri SA, Stein H, Thiele J, Vardiman JW. WHO classification of tumours of haematopoietic and lymphoid tissues (4th ed). Lyon, France: International Agency for Research on Cancer. 2008.

2. Cafferty LL, Katz RL, Ordonez NG, Carrasco CH, Cabanillas FR. Fine needle aspiration diagnosis of intraabdominal and retroperitoneal lymphomas by a morphologic and immunocytochemical approach. Cancer 1990;65;72-77.

3. Skoog SJ, Evans CP, Hayward IJ, Griffin JL, Hitchcock CL. Flow cytometry of fine needle aspirations of the Sprague-Dawley rat testis: defining normal maturation and the effects of multiple biopsies. The Journal of urology 1991;146;620-623.

4. Zander DS, Iturraspe JA, Everett ET, Massey JK, Braylan RC. Flow cytometry. In vitro assessment of its potential application for diagnosis and classification of lymphoid processes in cytologic preparations from fine-needle aspirates. American journal of clinical pathology 1994;101;577-586.

5. Dunphy $\mathrm{CH}$, Ramos R. Combining fine-needle aspiration and flow cytometric immunophenotyping in evaluation of nodal and extranodal sites for possible lymphoma: a retrospective review. Diagnostic cytopathology 1997;16;200-206.

6. Zardawi IM, Jain S, Bennett G. Flow-cytometric algorithm on fine-needle aspirates for the clinical workup of patients with lymphadenopathy. Diagnostic cytopathology 1998;19;274-278.

7. Jeffers MD, Milton J, Herriot R, McKean M. Fine needle aspiration cytology in the investigation on non-Hodgkin's lymphoma. Journal of clinical pathology 1998;51;189-196.

8. Young NA, Al-Saleem TI, Ehya H, Smith MR. Utilization of fine-needle aspiration cytology and flow cytometry in the diagnosis and subclassification of primary and recurrent lymphoma. Cancer 1998;84;252-261.

9. Stewart CJ, Duncan JA, Farquharson M, Richmond J. Fine needle aspiration cytology diagnosis of malignant lymphoma and reactive lymphoid hyperplasia. Journal of clinical pathology 1998;51;197-203.

10. Nicol TL, Silberman M, Rosenthal DL, Borowitz MJ. The accuracy of combined cytopathologic and flow cytometric analysis of fine-needle aspirates of lymph nodes. American journal of clinical pathology 2000;114;18-28.

11. Landgren O, Porwit MacDonald A, Tani E et al. A prospective comparison of fine-needle aspiration cytology and histopathology in the diagnosis and classification of lymphomas. Hematol J 2004;5;69-76.

12. Zeppa P, Marino G, Troncone G et al. Fine-needle cytology and flow cytometry immunophenotyping and subclassification of non-Hodgkin lymphoma: a critical review of 307 cases with technical suggestions. Cancer 2004;102;55-65.

13. Bangerter M, Brudler O, Heinrich B, Griesshamnuer M. Fine needle aspiration cytology and flow cytometry in the diagnosis and subclassification of non-Hodgkin's lymphoma based on the World Health Organization classification. Acta cytologica 2007;51;390-398.

14. Swart GJ, Wright C, Brundyn $\mathrm{K}$ et al. Fine needle aspiration biopsy and flow cytometry in the diagnosis of lymphoma. Transfus Apher Sci 2007;37;71-79.

15. Barroca H, Marques C, Candeias J. Fine needle aspiration cytology diagnosis, flow cytometry immunophenotyping and histology in clinically suspected lymphoproliferative disorder: a comparative study. Acta cytologica 2008;52;124-132. 
16. Dong HY, Harris NL, Preffer FI, Pitman MB. Fine-needle aspiration biopsy in the diagnosis and classification of primary and recurrent lymphoma: a retrospective analysis of the utility of cytomorphology and flow cytometry. Mod Pathol 2001;14;472481.

17. Mayall F, Darlington A, Harrison B. Fine needle aspiration cytology in the diagnosis of uncommon types of lymphoma. Journal of clinical pathology 2003;56;821825 .

18. Mourad WA, Tulbah A, Shoukri M et al. Primary diagnosis and REAL/WHO classification of non-Hodgkin's lymphoma by fine-needle aspiration: cytomorphologic and immunophenotypic approach. Diagnostic cytopathology 2003;28;191-195.

19. Sigstad E, Dong HP, Davidson B, Berner A, Tierens A, Risberg B. The role of flow cytometric immunophenotyping in improving the diagnostic accuracy in referred fine-needle aspiration specimens. Diagnostic cytopathology 2004;31;159-163.

20. Laane E, Tani E, Bjorklund E et al. Flow cytometric immunophenotyping including Bcl-2 detection on fine needle aspirates in the diagnosis of reactive lymphadenopathy and non-Hodgkin's lymphoma. Cytometry 2005;64;34-42.

21. Hajdu SI, Melamed MR. Limitations of aspiration cytology in the diagnosis of primary neoplasms. Acta cytologica 1984;28;337-345.

22. Carter TR, Feldman PS, Innes DJ, Jr., Frierson HF, Jr., Frigy AF. The role of fine needle aspiration cytology in the diagnosis of lymphoma. Acta cytologica 1988;32;848-853.

23. Wakely PE, Jr. Fine-needle aspiration cytopathology in diagnosis and classification of malignant lymphoma: accurate and reliable? Diagnostic cytopathology 2000;22;120-125.

24. Hehn ST, Grogan TM, Miller TP. Utility of fine-needle aspiration as a diagnostic technique in lymphoma. J Clin Oncol 2004;22;3046-3052.

25. Ravinsky E, Morales C, Kutryk E, Chrobak A, Paraskevas F. Cytodiagnosis of lymphoid proliferations by fine needle aspiration biopsy. Adjunctive value of flow cytometry. Acta cytologica 1999;43;1070-1078.

26. Henrique RM, Sousa ME, Godinho MI, Costa I, Barbosa IL, Lopes CA. Immunophenotyping by flow cytometry of fine needle aspirates in the diagnosis of lymphoproliferative disorders: A retrospective study. Journal of clinical laboratory analysis 1999;13;224-228.

27. Meda BA, Buss DH, Woodruff RD et al. Diagnosis and subclassification of primary and recurrent lymphoma. The usefulness and limitations of combined fineneedle aspiration cytomorphology and flow cytometry. American journal of clinical pathology 2000;113;688-699.

28. Liu K, Stern RC, Rogers RT, Dodd LG, Mann KP. Diagnosis of hematopoietic processes by fine-needle aspiration in conjunction with flow cytometry: A review of 127 cases. Diagnostic cytopathology 2001;24;1-10.

29. Bangerter M, Hildebrand A, Griesshammer M. Combined cytomorphologic and immunophenotypic analysis in the diagnostic workup of lymphomatous effusions. Acta cytologica 2001;45;307-312.

30. Gong JZ, Williams DC, Jr., Liu K, Jones C. Fine-needle aspiration in nonHodgkin lymphoma: evaluation of cell size by cytomorphology and flow cytometry. American journal of clinical pathology 2002;117;880-888.

31. Demurtas A, Accinelli G, Pacchioni D et al. Utility of Flow Cytometry Immunophenotyping in Fine-needle Aspirate Cytologic Diagnosis of Non-Hodgkin Lymphoma: A Series of 252 Cases and Review of the Literature. Appl Immunohistochem Mol Morphol 2009. 
32. Katz RL. Controversy in fine-needle aspiration of lymph nodes. A territorial imperative? American journal of clinical pathology 1997;108;S3-5.

33. Sandhaus LM. Fine-needle aspiration cytology in the diagnosis of lymphoma. The next step. American journal of clinical pathology 2000;113;623-627.

34. Siebert JD, Weeks LM, List LW et al. Utility of flow cytometry immunophenotyping for the diagnosis and classification of lymphoma in community hospital clinical needle aspiration/biopsies. Archives of pathology \& laboratory medicine 2000;124;1792-1799.

35. Greer JP, Macon WR, Lamar RE et al. T-cell-rich B-cell lymphomas: diagnosis and response to therapy of 44 patients. J Clin Oncol 1995;13;1742-1750.

36. Robins DB, Katz RL, Swan F, Jr., Atkinson EN, Ordonez NG, Huh YO. Immunotyping of lymphoma by fine-needle aspiration. A comparative study of cytospin preparations and flow cytometry. American journal of clinical pathology 1994;101;569576.

37. Mathiot C, Decaudin D, Klijanienko J et al. Fine-needle aspiration cytology combined with flow cytometry immunophenotyping is a rapid and accurate approach for the evaluation of suspicious superficial lymphoid lesions. Diagnostic cytopathology 2006;34;472-478.

38. Stewart FW. The diagnosis of tumors. The American journal of pathology 1933;9(Suppl);801-813.

39. Godwin JT. Aspiration biopsy: technique and application. Annals of the New York Academy of Sciences 1956;63;1348-1373.

40. Cardozo P. The cytologic diagnosis of lymph node punctures. Acta cytologica 1984;8;194-205.

41. Disbrey B, Rack J. Histological Laboratory Methods 1970.

42. Bahr GF. Some considerations of basic cell Chemistry. Compendium in cytopreparatory techniques. Tutorials of Cytology 1974;4th edition;1-6.

43. Danos M. Fixatives for cytologic use. In: Keebler CM, Reagan JW, Wied GL, editors. Compandium on cytopreparatory techniques, 4th ed. Chicago

Tutorials of Cytology 1976;7-9.

44. Gubin D. Hematoxylin-and-eosin staining of fine needle aspirate smears. Acta cytologica $1985 ; 29 ; 648-650$.

45. Abati A, Fetsch P, Filie A. If cells could talk. The application of new techniques to cytopathology. Clinics in laboratory medicine 1998;18;561-583.

46. Sanchez ML, Almeida J, Vidriales B et al. Incidence of phenotypic aberrations in a series of 467 patients with B chronic lymphoproliferative disorders: basis for the design of specific four-color stainings to be used for minimal residual disease investigation. Leukemia 2002;16;1460-1469.

47. Almeida M, Cordero M, Almeida J, Orfao A. Different subsets of peripheral blood dendritic cells show distinct phenotypic and functional abnormalities in HIV-1 infection. AIDS (London, England) 2005;19;261-271.

48. Quijano S, Lopez A, Manuel Sancho J et al. Identification of leptomeningeal disease in aggressive B-cell non-Hodgkin's lymphoma: improved sensitivity of flow cytometry. J Clin Oncol 2009;27;1462-1469.

49. Menendez P, Vargas A, Bueno C et al. Quantitative analysis of bcl-2 expression in normal and leukemic human B-cell differentiation. Leukemia 2004;18;491-498. 
50. Sevilla DW, Gong JZ, Goodman BK et al. Clinicopathologic findings in highgrade B-cell lymphomas with typical Burkitt morphologic features but lacking the MYC translocation. American journal of clinical pathology 2007;128;981-991.

51. van Dongen JJ, Langerak AW, Bruggemann M et al. Design and standardization of PCR primers and protocols for detection of clonal immunoglobulin and T-cell receptor gene recombinations in suspect lymphoproliferations: report of the BIOMED-2 Concerted Action BMH4-CT98-3936. Leukemia 2003;17;2257-2317.

52. Evans PA, Pott C, Groenen PJ et al. Significantly improved PCR-based clonality testing in B-cell malignancies by use of multiple immunoglobulin gene targets. Report of the BIOMED-2 Concerted Action BHM4-CT98-3936. Leukemia 2007;21;207-214.

53. Bruggemann $\mathrm{M}$, White $\mathrm{H}$, Gaulard $\mathrm{P}$ et al. Powerful strategy for polymerase chain reaction-based clonality assessment in T-cell malignancies Report of the BIOMED-2 Concerted Action BHM4 CT98-3936. Leukemia 2007;21;215-221.

54. Tabernero D, San Miguel JF, Garcia-Sanz M et al. Incidence of chromosome numerical changes in multiple myeloma: fluorescence in situ hybridization analysis using 15 chromosome-specific probes. The American journal of pathology 1996;149;153-161.

55. Quijano S, Lopez A, Rasillo A et al. Impact of trisomy 12, del(13q), del(17p), and del(11q) on the immunophenotype, DNA ploidy status, and proliferative rate of leukemic B-cells in chronic lymphocytic leukemia. Cytometry 2008;74;139-149.

56. Nieto WG, Almeida J, Romero A et al. Increased frequency (12\%) of circulating chronic lymphocytic leukemia-like B-cell clones in healthy subjects using a highly sensitive multicolor flow cytometry approach. Blood 2009;114;33-37.

57. Chhieng DC, Cohen JM, Cangiarella JF. Cytology and immunophenotyping of low- and intermediate-grade B-cell non-Hodgkin's lymphomas with a predominant small-cell component: a study of 56 cases. Diagnostic cytopathology 2001;24;90-97.

58. Dey P, Amir T, Al Jassar A et al. Combined applications of fine needle aspiration cytology and flow cytometric immunphenotyping for diagnosis and classification of non Hodgkin lymphoma. CytoJournal 2006;3;24.

59. Simsir A, Fetsch P, Stetler-Stevenson M, Abati A. Immunophenotypic analysis of non-Hodgkin's lymphomas in cytologic specimens: a correlative study of immunocytochemical and flow cytometric techniques. Diagnostic cytopathology 1999;20;278-284.

60. Russell J, Orell S, Skinner J, Seshadri R. Fine needle aspiration cytology in the management of lymphoma. Australian and New Zealand journal of medicine 1983;13;365-368.

61. Pontifex AH, Haley L. Fine-needle aspiration cytology in lymphomas and related disorders. Diagnostic cytopathology 1989;5;432-435.

62. Salameire D, Le Bris Y, Fabre B et al. Efficient characterization of the TCR repertoire in lymph nodes by flow cytometry. Cytometry A 2009;75;743-751.

63. Chung J, Gong G, Huh J, Khang SK, Ro JY. Flow cytometric immunophenotyping in fine-needle aspiration of lymph nodes. Journal of Korean medical science 1999;14;393-400.

64. Mayall F, Dray M, Stanley D, Harrison B, Allen R. Immunoflow cytometry and cell block immunohistochemistry in the FNA diagnosis of lymphoma: a review of 73 consecutive cases. Journal of clinical pathology 2000;53;451-457.

65. Gupta R, Naseem S, Kashyap R, Paul L. Role of fine-needle aspirate immunophenotyping by flow cytometry in rapid diagnosis of lymphoproliferative disorders. Diagnostic cytopathology 2007;35;381-385. 
66. Fromm JR, Thomas A, Wood BL. Flow cytometry can diagnose classical hodgkin lymphoma in lymph nodes with high sensitivity and specificity. American journal of clinical pathology 2009;131;322-332.

67. Bertram HC, Check IJ, Milano MA. Immunophenotyping large B-cell lymphomas. Flow cytometric pitfalls and pathologic correlation. American journal of clinical pathology 2001;116;191-203.

68. Mourad WA, al Nazer M, Tulbah A. Cytomorphologic differentiation of Hodgkin's lymphoma and $\mathrm{Ki}-1+$ anaplastic large cell lymphoma in fine needle aspirates. Acta cytologica 2003;47;744-748.

69. Snuderl M, Kolman OK, Chen YB et al. B-cell lymphomas with concurrent IGH-BCL2 and MYC rearrangements are aggressive neoplasms with clinical and pathologic features distinct from Burkitt lymphoma and diffuse large B-cell lymphoma. Am J Surg Pathol 2010;34;327-340. 


\section{Table 1}

Distribution of samples showing concordant results by screening flow cytometry (FCM) immunophenotyping and conventional cytology according to diagnosis

\begin{tabular}{lc}
\hline \multicolumn{1}{c}{ Diagnosis } & N. of FNA samples/ total samples $(\%)$ \\
\hline RP or HL & $181 / 184(98 \%)$ \\
Type I lymphadenitis & $35 / 35^{* *}$ \\
Type II lymphadenitis & $36 / 37 * *$ \\
Other reactive processes & $83 / 83 * *$ \\
HL & $27 / 29 * *$ \\
B-NHL & $121 / 132(92 \%)$ \\
T-NHL & $6 / 12(50 \%)$ \\
ST & $47 / 49(96 \%)$ \\
PCM & $11 / 14(79 \%)$ \\
AML & $1 / 2(50 \%)$ \\
T-ALL & $5 / 5(100 \%)$ \\
pDCN & $0 / 1(0 \%)$ \\
\hline Total samples & $372 / 399(93 \%)$ \\
\hline
\end{tabular}

Results expressed as number of concordant samples/total samples (percentage between brackets) within each diagnostic group. ** unclassifiable by FCM.

FCM: flow cytometry; FNA: fine-needle aspirate sample; RP: reactive process; HL: Hodgkin's lymphoma. B-NHL: B-cell non-Hodgkin lymphoma; T-NHL: T-cell non-Hodgkin lymphoma; ST: solid tumor; PCM: plasma cell malignancy; AML: acute myeloid leukemia; T-ALL: T-cell acute lymphoblastic leukemia; pDCN: blastic plasmacytoid dendritic cell neoplasm. 
Table 2

Discordant results between FCM, conventional cytology and

histopathology at diagnostic screening

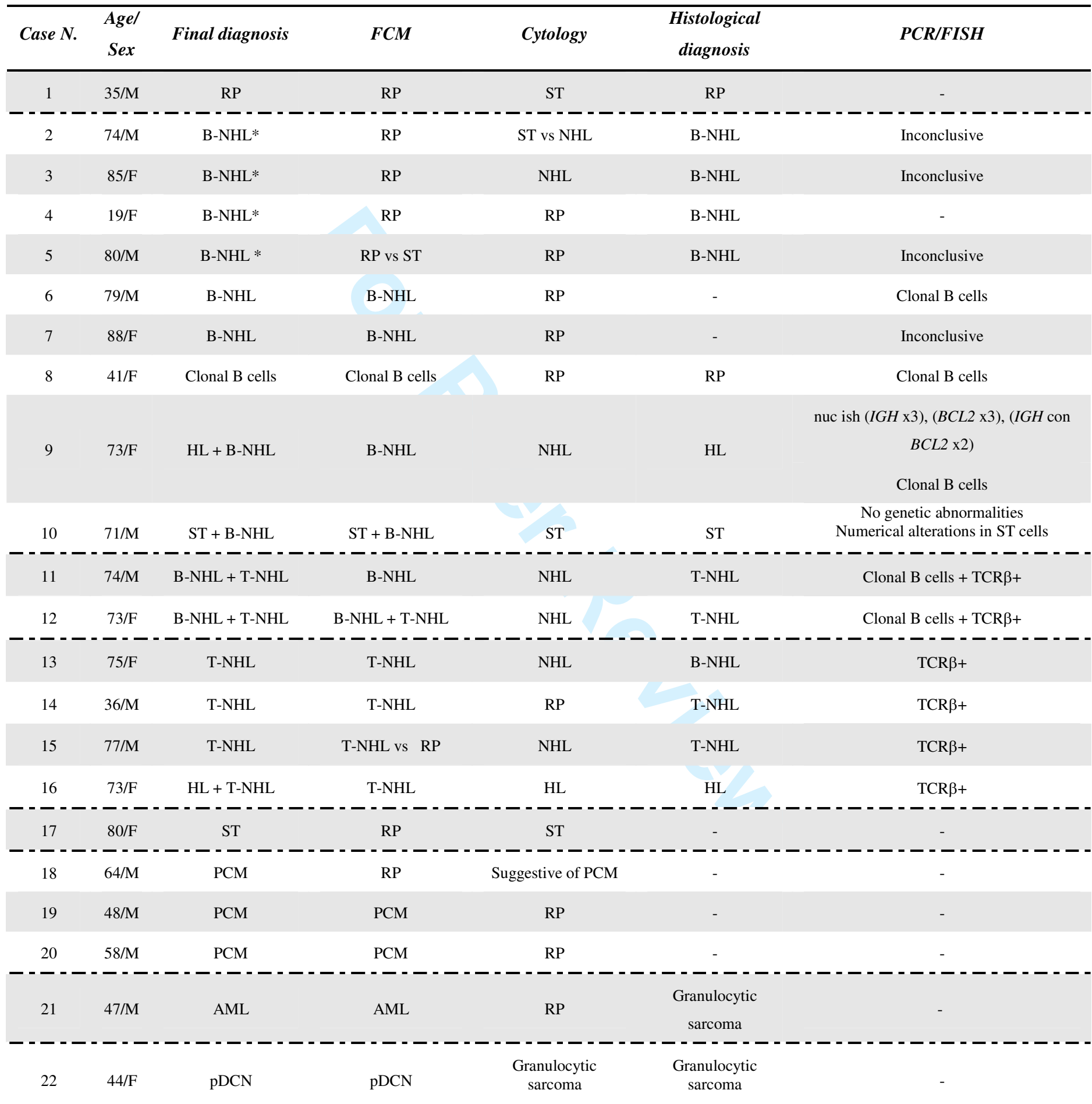

FCM: flow cytometry: PCR: polymerase chain reaction; FISH: fluorescence in situ hybridization; M: male; F: female; RP: reactive process; ST: solid tumor; AML: acute myeloid leukemia; PCM: plasma cell malignancy; pDCN: blastic plasmacytoid dendritic cell neoplasm; HL: Hodgkin`s lymphoma; B-NHL: B-cell non-Hodgkin lymphoma; T-NHL: T-cell non-Hodgkin lymphoma; -: not determined.

* Final diagnosis was established on the basis of both histopathological features $\left(\mathrm{CD} 20^{+} / \mathrm{Ki} 67^{+/++}\right.$large cells, usually showing diffuse pattern of tissue infiltration) and clinical follow-up. Neither kappa/lambda analysis by immunohistochemistry nor molecular/genetic evaluations were conclusive. 


\section{Table 3}

Sensitivity (PPV) and specificity (NPV) of FCM vs conventional cytology for the diagnostic screening of FNA samples from patients with a complete diagnostic work up ( $n=167)$ (upper panel), including the specific classification of $B-N H L / B-$ CLPD samples (n=82) into specific WHO disease entities (lower panel)

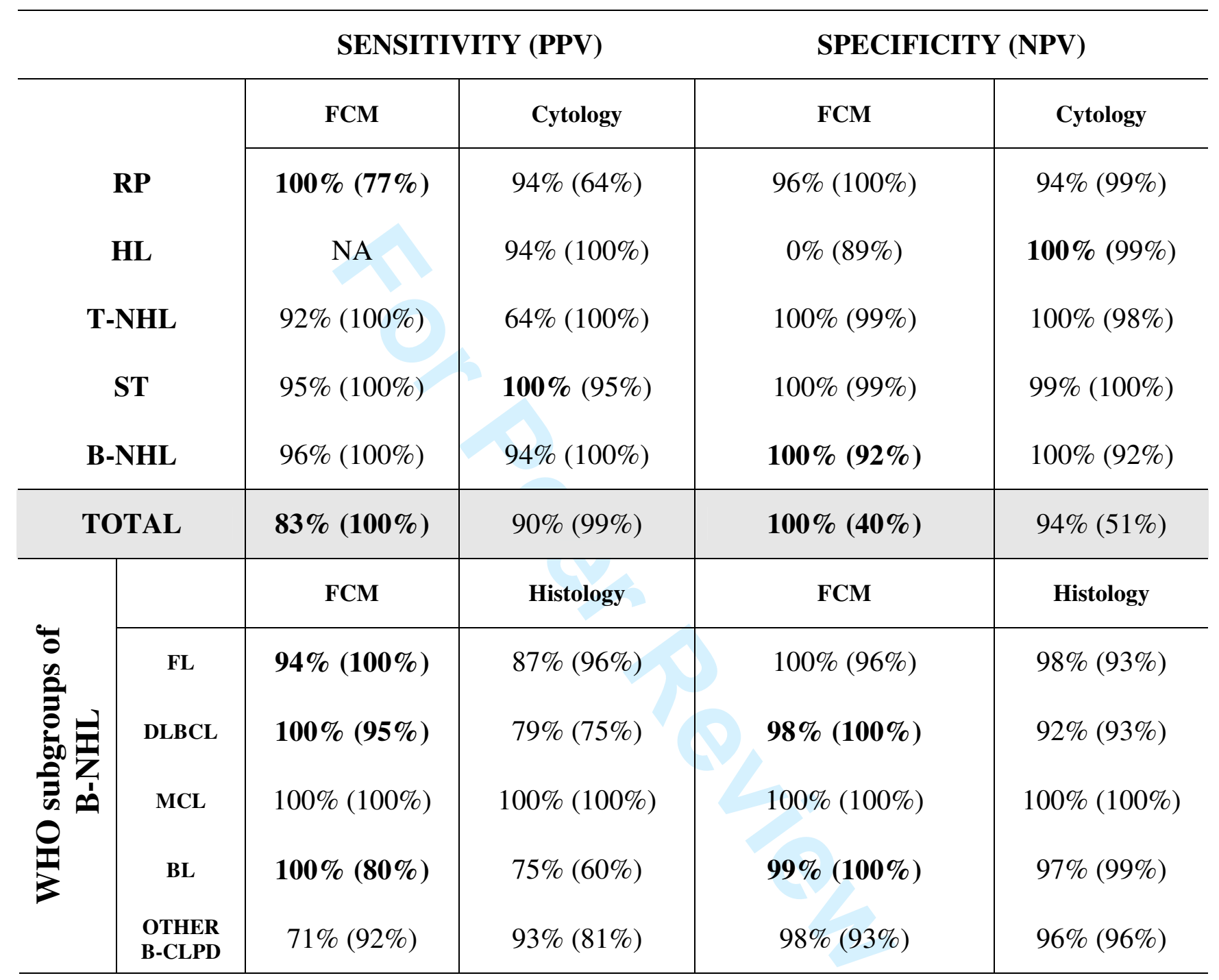

FCM: flow cytometry; PPV: positive predictive value; NPV: negative predictive value; RP: reactive process; HL: Hodgkin`s lymphoma; B-NHL: B-cell non-Hodgkin lymphoma; FL: follicular lymphoma; DLBCL: diffuse large B-cell lymphoma; MCL: mantle cell lymphoma, BL: Burkitt`s lymphoma; T-NHL: T-cell non Hodgkin lymphoma; ST: solid tumor; CLPD: chronic lymphoproliferative disorder. 


\section{Table 4}

\section{Subclassification of B-NHL into WHO diagnostic categories: discordant results between FCM and histopathology}

\begin{tabular}{|c|c|c|c|c|c|c|}
\hline Case $N$. & Age/Sex & Final diagnosis & FCM diagnosis & $\begin{array}{c}\text { Histopathological } \\
\text { diagnosis }\end{array}$ & iFISH cytogenetics & iFISH Probes tested \\
\hline 1 & 33/M & FL & NHL (FSC/SSC $\left.{ }^{\text {intermediate }}\right)^{*}$ & FL & $\begin{array}{l}\text { nuc ish }(B C L 6 \times 3)[48 / 200] \\
\text { nuc ish }(I G H \times 2)\left(5^{\prime} I G H \text { sep } 3^{\prime} I G H \times 1\right)[42 / 110]\end{array}$ & $\begin{array}{l}\text { LSI BCL6, LSI IgH/MYC/CEP8, LSI IgH, LSI } \\
\text { IgH/CCND1, LSI IgH/BCL2, LSI MALT1, }\end{array}$ \\
\hline 2 & $44 / \mathrm{M}$ & FL & NHL (FSC/SSC low $)^{* *}$ & $\mathrm{FL}$ & No abnormalities & LSI MYC, LSI IgH/BCL2 \\
\hline 3 & $50 / \mathrm{M}$ & FL & FL & DLBCL & nuc ish $(M A L T \times 3)[40 / 100]$ & LSI BCL6, LSI IgH/BCL2, LSI MALT1 \\
\hline 4 & $47 / F$ & FL & FL & DLBCL & nuc ish $(I G H \times 3),(B C L 2 \times 3),(I G H \operatorname{con} B C L 2 \times 2)[47 / 116]$ & LSI BLC6, LSI IgH/MYC/CEP8, LSI IgH/BCL2 \\
\hline 5 & 69/M & FL & FL vs tFL & DLBCL & nuc ish $(I G H \times 3),(B C L 2 \times 3),(I G H \operatorname{con} B C L 2 \times 2)[86 / 100]$ & LSI IgH/BCL2, LSI BCL6 \\
\hline$\frac{6}{7}+\#$ & $\frac{76 / \mathrm{M}}{72 / \mathrm{F}}$ & $-\frac{\mathrm{tFL}(\bullet)}{\mathrm{BL}}-$ & 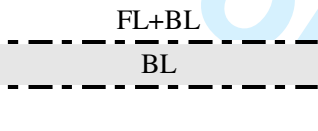 & $--\frac{B L}{D L B C L}-$ & $\begin{array}{l}\text { nuc ish }(I G H \times 3),(B C L 2 \times 3),(I G H \text { con } B C L 2 \times 2)[52 / 100] \\
\text { nuc ish }(C-M Y C \times 3) \\
\text { i nuc ish }(C C N D 1 \times 3)\end{array}$ & 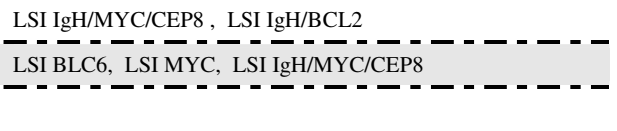 \\
\hline 8(\#) & $82 / \mathrm{M}$ & nMZL & $\mathrm{CLL}+\mathrm{NHL}$ & MZL & $\begin{array}{l}\text { ii idem }(I G H \times 4),(M A L T-1 \times 6)[63 / 100] \\
\text { iii idem }(I G H, M A L T-1) \times 5[15 / 100]\end{array}$ & LSI IgH/CCND1， LSI IgH/BCL2 \\
\hline 9 & $60 / \mathrm{F}$ & nMZL & NHL $\left(\text { FSC/SSC }{ }^{\text {intermediate }}\right)^{*}$ & MZL & No abnormalities & LSI D7S486/CEP7 (7q31/7P11.1-q11.1), LSI IgH/BCL2 \\
\hline 10 & $\frac{58 / \mathrm{F}}{67 / \mathrm{F}}$ & $-\overline{\text { MALT }}=\frac{\mathrm{nMZL}}{\mathrm{Lymph}}-\overline{-}$ & $-\frac{\mathrm{NHL}^{*}}{\mathrm{DLBCL}}--$ & $-\overline{M A L T}-\frac{\text { MZL }}{\text { Lymphoma }}-$ & $\begin{array}{l}\text { No abnormalities } \\
\text { No abnormalities }\end{array}$ & $\begin{array}{l}\mathrm{LSI} I \mathrm{IgH}, \mathrm{LSI} \operatorname{LgH} / \mathrm{BCL} 2 \\
\mathrm{LSI} \operatorname{IgH} / \mathrm{BCL} 2\end{array}$ \\
\hline$\frac{12}{13}$ & $\frac{62 / M}{61 / M}$ & MALT Lymphoma & $\begin{array}{l}\mathrm{NHL}^{*} \\
\mathrm{sMZL} \\
\mathrm{SM}\end{array}$ & $\begin{array}{l}--\frac{\text { MZL }}{-----} \\
\text { MALT Lymphoma }\end{array}$ & $\begin{array}{l}\text { nuc ish }(I G H, B C L 2) \times 3 \text { [16/100] }----1- \\
\text { nuc ish }(B C L 6, M A L T 1) \times 3[13 / 100],[22 / 200]\end{array}$ & 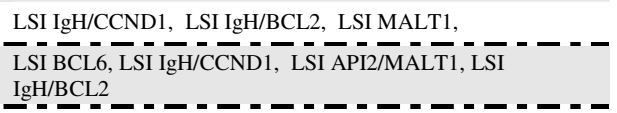 \\
\hline 14 & 74/M & DLBCL & DLBCL & FL GRADE II & $\begin{array}{l}\text { i nuc ish }(B C L 6 \times 3)[30 / 200] \\
\text { ii idem }(B C L 6 \times 4) \text { [102/200] }\end{array}$ & $\begin{array}{l}\text { LSI BCL6, LSI IgH/MYC/CEP8, LSI IgH/BCL2, LSI } \\
\text { MALT1 }\end{array}$ \\
\hline 15 & 48/M & DLBCL & DLBCL(2) & BL & No abnormalities & LSI MYC, LSI IgH/CCND1, LSI IgH/BCL2 \\
\hline 16 & 74/F & DLBCL & LBCL & B-CLPD. & No abnormalities & LSI IgH/MYC/CEP8 \\
\hline 17 & $81 / \mathrm{M}$ & LPL & LPL vs LBCL & DLBCL & $\begin{array}{l}\text { i nuc ish }(S E C 63 \times 1),(I G H \times 2)\left(5^{\prime} I G H \text { sep 3'IGH } \times 1\right)[55 / 98] \\
\text { ii idem }(C-M Y C \times 3)[25 / 100]\end{array}$ & $\begin{array}{l}\text { LSI BCL6, } 6 \text { q21 specific/ } \alpha \text {-satellite } 6 \text { Probe Cocktail, LSI } \\
\text { IgH, LSI IgH/MYC/CEP8, LSI IgH/BCL2 }\end{array}$ \\
\hline 18 & $89 / \mathrm{F}$ & LPL & LPL & MZL & No abnormalities & LSI IgH/CCND1, LSI IgH/BCL2 \\
\hline
\end{tabular}

FCM: flow cytometry; NHL: non-Hodgkin lymphoma; FL: follicular lymphoma; DLBCL: diffuse large B-cell lymphoma; tFL: transformed follicular lymphoma; BL: Burkitt`s lymphoma; CLL: B-cell chronic lymphocytic leukemia; LBCL: large B-cell lymphoma; MALT: mucosa-associated lymphoid tissue; nMZL: nodal zone marginal lymphoma; sMZL: splenic zone marginal lymphoma; LPL: lymphoplasmacytic lymphoma. B-CLPD: B-cell chronic lymphoproliferative disorder not specified. The specific loci involved in the translocations analyzed are described in the Material and Methods section.

*: atypical immunophenotype different from CLL, mantle cell lymphoma (MCL), hairy cell leukemia (HCL), FL, BL, DLBCL, sMZL, immunoblastic lymphoma, B-lymphoblastic lymphoma and compatible with other B-NHL.

**: different from typical $t(14 ; 18)+\mathrm{FL}$

(\#)Two aberrant B-cell populations were identified by FCM but not by histopathology.

(2) Two samples, both from the same patient diagnosed with DLBCL from the same patient.

(•) Patient previously diagnosed as FL by histology. The FNA sample included in the present study was obtained at relapse. 
Supplementary Table 1a: Antibody (Ab) reagents and DNA probes used for the immunophenotypic and genetic characterization of FNA samples, respectively.

\begin{tabular}{|c|c|c|c|c|c|c|c|}
\hline \multicolumn{8}{|c|}{ FCM IMMUNOPHENOTYPING REAGENTS } \\
\hline Ab conjugates & Clone & Source & TUBE & Ab conjugates & Clone & Source & TUBE \\
\hline CD8 FITC & SK1 & $\mathrm{BDB}^{\mathrm{a}}$ & Screening & CD14 PCy7 & RMO52 & Immunotech $^{\mathrm{d}}$ & Tube 1 and $2 * * *$ \\
\hline CD56 PE & B159 & $\mathrm{BDB}^{\mathrm{a}}$ & Screening & CD40 APC & HB14 & Innogenetics ${ }^{\mathrm{b}}$ & Tube $1 * * *$ \\
\hline CD4 PerCP & SK3 & $\mathrm{BDB}^{\mathrm{a}}$ & Screening & $\mathrm{CD} 45 \mathrm{~PB}$ & $\mathrm{~T} 29 / 33$ & Palex $^{\mathrm{f}}$ & Tube 1 and $2 * * *$ \\
\hline CD19 PerCP & HIB19 & $\mathrm{BDB}^{\mathrm{a}}$ & Screening & CD36 FITC & FA6.152 & Immunotech $^{\mathrm{d}}$ & Tube $2 * * *$ \\
\hline CD3 APC and AmCyan & SK7 & $\mathrm{BDB}^{\mathrm{a}}$ & Screening & CD95 PE & $\mathrm{DX} 2$ & Pharmingen $^{\mathrm{b}}$ & Tube $2 * * *$ \\
\hline CD45 APCCy7 and FITC & 2D1 & $\mathrm{BDB}^{\mathrm{a}}$ & Screening and Tube $1 * *$, respectively & CD86 APC & 2331 (FUN-1) & Pharmingen ${ }^{\mathrm{b}}$ & Tube $2 * * *$ \\
\hline CD22 FITC & HIB22 & $\mathrm{BDB}^{\mathrm{a}}$ & Tube $1 *$ & Anti-HLADR PerCP & L243 & $\mathrm{BDB}^{\mathrm{a}}$ & Tube 1 and $2 * * *$ \\
\hline CD23 PE & EBVC35 & $\mathrm{BDB}^{\mathrm{a}}$ & Tube $1 *$ & CD71FITC & L01.1 & $\mathrm{BDB}^{\mathrm{a}}$ & Tube $1 * * *$ \\
\hline CD20 APC & $2 \mathrm{H} 7$ & $\mathrm{BDB}^{\mathrm{a}}$ & Tube $1 *$ & CD30 PE & BerH8 & Pharmingen ${ }^{\mathrm{b}}$ & Tube $1 * * *$ \\
\hline CD103 FITC & Ber-ACT8 & $\mathrm{BDB}^{\mathrm{a}}$ & Tube $2 *$ & CD94 FITC & HP3D9 & Pharmingen $^{\mathrm{b}}$ & Tube $1 * * * *$ \\
\hline CD25 PE & $2 \mathrm{~A} 3$ & $\mathrm{BDB}^{\mathrm{a}}$ & Tube $2 *$ & Anti-HLADR PE & L243(G46-6) & $\mathrm{BDB}^{\mathrm{a}}$ & Tube $1 * * * *$ \\
\hline CD11c APC & S-HCL-3 & $\mathrm{BDB}^{\mathrm{a}}$ & Tube $2 *$ & CD2 FITC & S5.2 & $\mathrm{BDB}^{\mathrm{a}}$ & Tube $2 * * * *$ \\
\hline CD43 FITC & $1 \mathrm{G} 10$ & $\mathrm{BDB}^{\mathrm{a}}$ & Tube $3 *$ & $\mathrm{CD} 28 \mathrm{PE}$ & L293 & $\mathrm{BDB}^{\mathrm{a}}$ & Tube $2 * * * *$ \\
\hline CD79b PE & $3 \mathrm{~A} 2-2 \mathrm{E} 7$ & $\mathrm{BDB}^{\mathrm{a}}$ & Tube $3 *$ & CD7 FITC & $4 \mathrm{H} 9$ & $\mathrm{BDB}^{\mathrm{a}}$ & Tube $3 * * * *$ \\
\hline CD49d APC & $9 \mathrm{~F} 10$ & Pharmingen $^{\mathrm{b}}$ & Tube $3 *$ & CD5 PE & L17F12 & $\mathrm{BDB}^{\mathrm{a}}$ & Tube $3 * * * *$ \\
\hline FMC7 FITC & FMC7 & $\mathrm{BDB}^{\mathrm{a}}$ & Tube $4 *$ & CD57 FITC & HNK-1 & $\mathrm{BDB}^{\mathrm{a}}$ & Tube $4 * * * *$ \\
\hline $\mathrm{CD} 24 \mathrm{PE}$ & ML5 & $\mathrm{BDB}^{\mathrm{a}}$ & Tube $4 *$ & CD11c PE & S-HCL.3 & $\mathrm{BDB}^{\mathrm{a}}$ & Tube $4 * * * *$ \\
\hline CD34 APC & $8 \mathrm{G} 12$ & $\mathrm{BDB}^{\mathrm{a}}$ & Tube $4 *$ & CD45RA FITC & L48 & $\mathrm{BDB}^{\mathrm{a}}$ & Tube $5 * * * *$ \\
\hline anti-sIgк FITC & Polyclonal & Dako $^{\mathrm{c}}$ & Tube $5 *$ & CCR7 PE & 150503 & R\&D Systems ${ }^{\mathrm{g}}$ & Tube $5 * * * *$ \\
\hline anti-sIg $\lambda$ PE & Polyclonal & Dako $^{c}$ & Tube $5 *$ & CD27 FITC & L128 & $\mathrm{BDB}^{\mathrm{a}}$ & Tube $6 * * * *$ \\
\hline CD5 APC & UCHT2 & $\mathrm{BDB}^{\mathrm{a}}$ & Tube $5 *$ & CD45RO PE & VCHL1 & $\mathrm{BDB}^{\mathrm{a}}$ & Tube $6 * * * *$ \\
\hline Anti-IgM FITC & Polyclonal & Dako $^{c}$ & Tube $4 *$ & Anti-TCR $\gamma \delta$ - PE & $11 \mathrm{~F} 2$ & $\mathrm{BDB}^{\mathrm{a}}$ & Tube $7 * * * *$ \\
\hline CD27 PE & L128 & $\mathrm{BDB}^{\mathrm{a}}$ & Tube $6 *$ & Anti-TCR $\alpha \beta$-FITC & WT31 & $\mathrm{BDB}^{\mathrm{a}}$ & Tube $7 * * * *$ \\
\hline CD38 APC & HIT2 & $\mathrm{BDB}^{\mathrm{a}}$ & Tube $7 *$ & Anti-Perforine FITC & $\delta \mathrm{G} 9$ & Pharmingen $^{\mathrm{b}}$ & Tube $8 * * * *$ \\
\hline Anti-Bcl2 FITC & 124 & $\operatorname{Dako}^{\mathrm{c}}$ & Tube $7 *$ & Anti-Granzyme PE & CLB-GB11 & Sanquin $^{\mathrm{h}}$ & Tube $8 * * * *$ \\
\hline CD10 PE & ALB1 & Immunotech $^{\mathrm{d}}$ & Tube $7 *$ & CD25 FITC & $2 \mathrm{~A} 3$ & $\mathrm{BDB}^{\mathrm{a}}$ & Tube $9 * * * *$ \\
\hline CD16 PE & $3 \mathrm{G} 8$ & Immunotech $^{\mathrm{d}}$ & Tube $1 * *$ & CD127 PE & Hil-7R-M21 & Pharmingen $^{\mathrm{b}}$ & Tube $9 * * * *$ \\
\hline Anti-Cytokeratin 18 & Ks 18.04 & Cytognos $^{\mathrm{e}}$ & Tube $2 * *$ & & & & \\
\hline
\end{tabular}

Abbreviations: Ab, antibodies; FITC, fluorescein isothiocyanate; PE, phycoerythrin; PerCP, peridinin chlorophyll protein; APC, allophycocyanin; AmCyan, Anemonia majano cyan; APCCy7, allophycocyanin-cyanin 7; PCy7, phycoerythrin-cyanin 7; PB, Pacific Blue. ${ }^{a}$ BDB: Becton/Dickinson Biosciences (San José, CA, USA); ${ }^{b}$ Pharmingen (BD Biosciences, San Diego, CA, USA); ${ }^{\circ}$ Dako (Glostrup, Denmark); ${ }^{\mathrm{d}}$ Immunotech (Marseille, France); ${ }^{\mathrm{e}}$ Cytognos (Salamanca, Spain); fPalex Medical (Barcelona, Spain); ${ }^{\mathrm{g}}$ R\&D Systems (Minneapolis, MN, USA); ${ }^{\mathrm{h}}$ Sanquin (Amsterdam); * from the B-cell non Hodgkin lymphoma extended panel; ** from the Solid Tumor extended panel; *** from the Hodgkin lymphoma extended panel; **** from the T-cell non Hodgkin lymphoma extended panel. 
Supplementary Table 1b: Antibody (Ab) reagents and DNA probes used for the immunophenotypic and genetic characterization of FNA samples, respectively

\begin{tabular}{|c|c|c|c|c|c|c|}
\hline \multicolumn{4}{|c|}{ IMMUNOCYTOCHEMISTRY /IMMUNOHISTOCHEMISTRY REAGENTS } & \multicolumn{3}{|c|}{ INTERPHASE FLUORESCENCE IN SITU HYBRIDIZATION (IFISH) PROBES } \\
\hline Ab conjugates & Clone & Source & Dilution & Genetic alteration & Probe & Source \\
\hline Anti-Igk & Polyclonal & Vitro & Freeze-dried & trisomy 12 & CEP12 & Vysis Inc ${ }^{1}$ \\
\hline Anti-Igl & Polyclonal & Vitro & Freeze-dried & $\operatorname{del}(11 \mathrm{q} 22.3)$ & LSI ATM (11q22.3) & Vysis Inc ${ }^{1}$ \\
\hline CD5 & $4 \mathrm{C} 7$ & $\mathrm{MD}^{\mathrm{i}}$ & $1: 50$ & $\operatorname{del}(11 \mathrm{q} 23)$ & LSI MLL (11q23.3) & Vysis Inc ${ }^{1}$ \\
\hline $\mathrm{CD} 20$ & $\mathrm{~L} 26$ & $\mathrm{MD}^{\mathrm{i}}$ & $1: 200$ & $\operatorname{del}(17 \mathrm{p} 13.1)$ & LSI p53 (17p13.1) & Vysis Inc ${ }^{1}$ \\
\hline CD10 & $56 \mathrm{C} 6$ & $\mathrm{MD}^{\mathrm{i}}$ & $1: 100$ & $\operatorname{del}(7 q)$ & LSI D7S486/CEP7 (7q31/7p11.1-q11.1) & Vysis Inc ${ }^{1}$ \\
\hline Anti-Bcl6 & BL6.02 & $\mathrm{MD}^{\mathrm{i}}$ & $1: 50$ & $\operatorname{del}(13 q 14)$ & LSI 13/RB1 gene (13q14) and LSI D13S25 (13q14.3) & Vysis Inc ${ }^{1}$ \\
\hline CD79a & HM47/A9 & $\mathrm{MD}^{\mathrm{i}}$ & $1: 80$ & $t(14 q 32)$ & LSI IgH & Vysis Inc ${ }^{1}$ \\
\hline $\mathrm{CD} 30$ & Ber-H2 & $\mathrm{MD}^{\mathrm{i}}$ & $1: 20$ & $t(18 \mathrm{q} 21)$ & LSI MALT1 & Vysis Inc ${ }^{1}$ \\
\hline Ki67 & SP6 & $\mathrm{MD}^{\mathrm{i}}$ & $1: 80$ & $\mathrm{t}(14 ; 18)(\mathrm{q} 32 ; \mathrm{q} 21)$ & LSI IgH/BCL2 & Vysis Inc ${ }^{1}$ \\
\hline Anti-Cyclin D1 & SP4 & $\mathrm{BM}^{\mathrm{j}}$ & Prediluted & $\mathrm{t}(11 ; 14)(\mathrm{q} 13 ; \mathrm{q} 32)$ & LSI IgH/CCND1 & Vysis Inc ${ }^{1}$ \\
\hline Anti-Pax 5 & $\mathrm{BC} / 24$ & $\mathrm{BM}^{\mathrm{j}}$ & $1: 20$ & $\mathrm{t}(8 ; 14)(\mathrm{q} 24 ; \mathrm{q} 32)$ & LSI IgH/MYC/CEP8 & Vysis Inc ${ }^{1}$ \\
\hline CD3 & PS1 & Novocastra $^{\mathrm{k}}$ & Prediluted & $\mathrm{t}(11 ; 18)(\mathrm{q} 21 ; \mathrm{q} 21)$ & LSI API2/MALT1 & Vysis Inc ${ }^{1}$ \\
\hline \multirow[t]{3}{*}{ Anti-Bcl2 } & 3.1 & Novocastra $^{\mathrm{k}}$ & $1: 20$ & $\mathrm{c}-\mathrm{MYC}$ & LSI MYC & Vysis Inc ${ }^{1}$ \\
\hline & & & & BCL6 & LSI BCL6 & Vysis Inc ${ }^{1}$ \\
\hline & & & & $\operatorname{del}(6 q 21)$ & 6q21 specific / $\alpha$-satellite 6 Probe Cocktail & QBiogene $^{\mathrm{m}}$ \\
\hline
\end{tabular}




\section{SUPPLEMENTARY TEXT RESULTS}

Flow cytometry distribution of lymphocyte subsets in lymph node FNA samples with concordant diagnoses $(n=323)$. Overall, FNA samples infiltrated with TNHL showed a significantly $(\mathrm{p}<0.04)$ higher percentage of $\mathrm{T}$ cells than those corresponding to B-NHL, ST, PCM and T-ALL, but similar to those from individuals with RP and HL ( $\mathrm{p}>0.05$ ) (Figure 1A). A similar distribution to that of mature CD3+ T lymphocytes was also found among the different diagnostic groups for the major CD4+, and to a lower extent, also CD8+ T-cell subsets (Figure $1 \mathrm{~B}-\mathrm{C}$ ). HL showed the highest $\mathrm{CD}^{+} / \mathrm{CD}^{+} \mathrm{T}$-cell ratio values, which were significantly greater than those of $\mathrm{RP}, \mathrm{B}-$ NHL and PCM samples (Figure 1F). The minor CD4+/CD8+ and CD4-/CD8- T-cell phenotypes were particularly increased among T-NHL specimens. (Figures 1 D-E)

Overall, B cell numbers were significantly higher among B-NHL vs all other groups $(\mathrm{p} \leq 0.01$; Figure $1 \mathrm{G})$. In addition, once $\operatorname{sIg} \kappa^{+}$B-NHL and $\operatorname{sIg} \lambda^{+}$B-NHL cases were separately considered, the percentage of either $\operatorname{sIg} \kappa^{+}$and $\operatorname{sIg} \lambda^{+} \mathrm{B}$ cells was significantly higher among B-NHL vs all other groups; similarly, the $\kappa / \lambda$ ratio was higher $(\mathrm{p} \leq 0.02)$ among the $\operatorname{sIg} \kappa^{+} \mathrm{B}-\mathrm{NHL}$ and lower $(\mathrm{p} \leq 0.03)$ whitin the $\operatorname{sIg} \lambda^{+} \mathrm{B}-\mathrm{NHL}$ vs all other groups. A variable infiltration by $\mathrm{CD} 45^{-}$non-hematopoietic and plasma cells was found in ST $(48 \% \pm 32 \%)$ and PCM $(70 \% \pm 34 \%)$, respectively, while irrelevant $(<1 \%)$ among other cases. Presence of blast cells was restricted to T-ALL samples (data not shown). 
Supplementary Figure 1
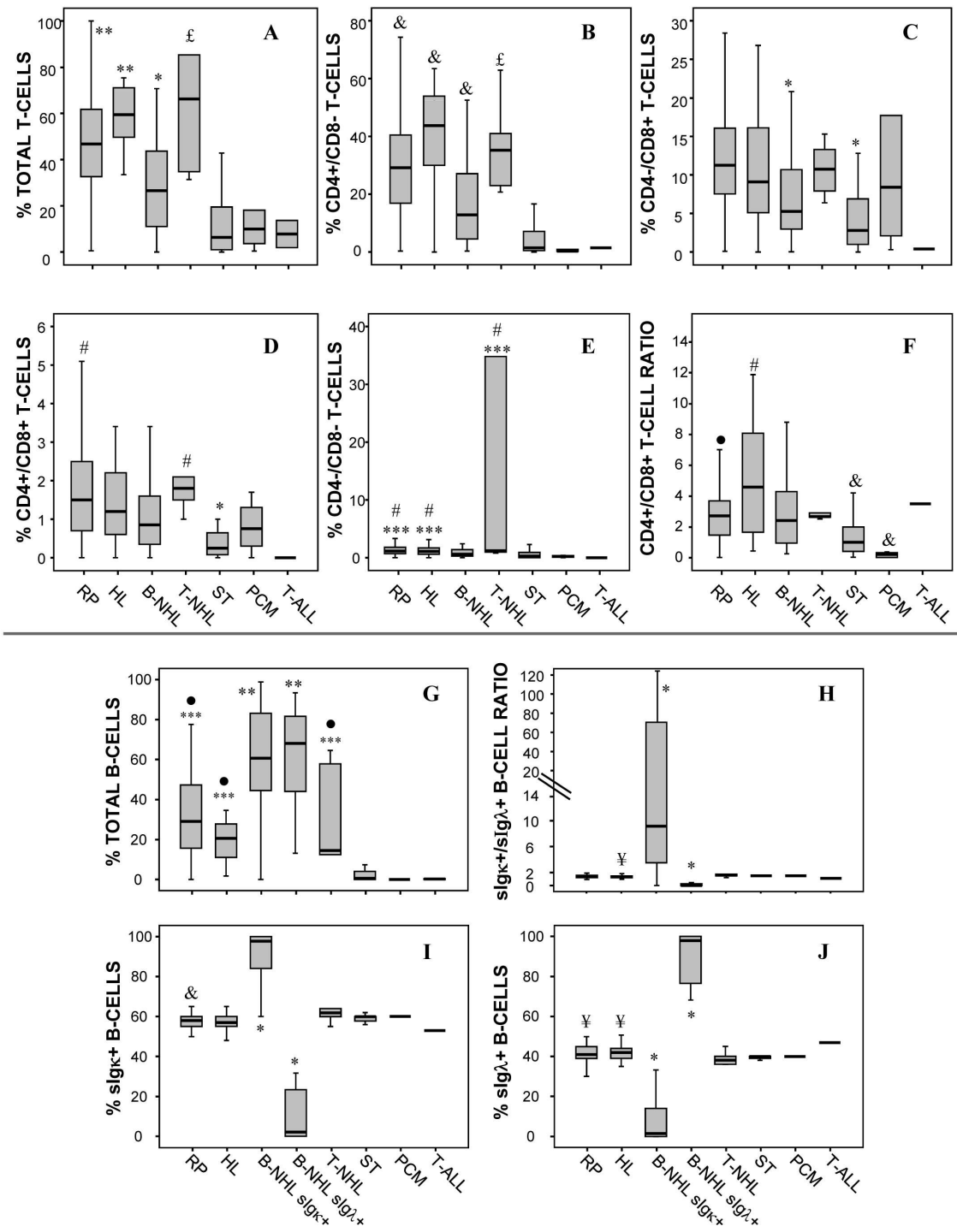

$190 \times 254 \mathrm{~mm}(300 \times 300$ DPI $)$ 


\section{Figure legends}

Supplementary Figure 1.- Relative distribution of T-lymphocyte (panels A-F) and Bcell (Panels E-J) subsets in lymph node samples with concordant flow cytometry and cytological diagnosis $(n=323$ ) distributed according to final diagnosis (results expressed as percentage of cells from the whole sample). In panels $\mathrm{H}-\mathrm{J}$ the $\operatorname{sIg} \kappa^{+} / \mathrm{sIg} \lambda^{+}$ratio from B-NHL is separately shown for $\operatorname{sIg} \kappa^{+}$B-NHL and $\operatorname{sIg} \lambda^{+}$B-NHL. Boxes extend from the $25^{\text {th }}$ to the $75^{\text {th }}$ percentiles; the line in the middle represents median values, while vertical lines represent the highest and lowest values (excluding outliers and extreme values). Panels A-F: * $\mathrm{p} \leq 0.05$ vs all other groups except T-ALL and PCM; ** $\mathrm{p} \leq 0.05$ vs all other groups; *** $\mathrm{p} \leq 0.05$ vs PCM and ST; $\# \mathrm{p} \leq 0.05$ vs B-NHL; $\& \mathrm{p} \leq 0.05$ vs all other groups, except T-ALL; $£ \mathrm{p} \leq 0.05$ vs all other groups except RLN and HL; $\bullet \mathrm{p} \leq 0.05$ vs HL. Panels G-J: ${ }^{*} \mathrm{p} \leq 0.05$ vs all other groups, except T-ALL; ** $\mathrm{p} \leq 0.05$ vs all other groups; $* * * \mathrm{p} \leq 0.05$ vs PCM and ST; $\& \mathrm{p} \leq 0.05$ vs T-NHL; $¥ \mathrm{p} \leq 0.05$ vs $\mathrm{ST} ; \bullet \mathrm{p} \leq 0.05$ vs T-ALL. RP: reactive process; HL: Hodgkin`s Lymphoma; B-NHL: B- Non Hodgkin Lymphoma; T-NHL: T-Non Hodgkin Lymphoma; ST: solid tumor; PCM: Plasma Cell Malignancy; T-ALL: T-Acute Lymphoblastic Leukemia. 